\title{
Implication of right ventricular dysfunction on long-term outcome in patients with ischemic cardiomyopathy undergoing coronary artery bypass grafting with or without surgical ventricular reconstruction
}

Tomasz Kukulski, MD, PhD, ${ }^{\mathrm{a}}$ Lilin She, $\mathrm{PhD},{ }^{\mathrm{b}}$ Normand Racine, $\mathrm{MD},{ }^{\mathrm{e}}$ Sinisa Gradinac, $\mathrm{MD},{ }^{\mathrm{f}}$ Julio A. Panza, MD, ${ }^{\mathrm{g}}$ Eric J. Velazquez, MD, ${ }^{\mathrm{b}, \mathrm{c}}$ Kwan Chan, MD, ${ }^{\mathrm{h}}$ Mark C. Petrie, MD, Kerry L. Lee, PhD, ${ }^{b, d}$ Patricia A. Pellikka, MD ${ }^{j}$ Alexander Romanov, MD, ${ }^{k}$ Jolanta Biernat, MD, Jean L. Rouleau, MD, ${ }^{\mathrm{e}}$ Carmen Batlle, MD, ${ }^{\mathrm{m}}$ Jan Rogowski, MD,${ }^{\mathrm{n}}$ Paolo Ferrazzi, MD, ${ }^{\circ}$ Marian Zembala, MD, ${ }^{a}$ and Jae K. Oh, MD, ${ }^{j}$ for the Surgical Treatment for Ischemic Heart Failure Investigators

Objective: Whether right ventricular dysfunction affects clinical outcome after coronary artery bypass grafting with or without surgical ventricular reconstruction is still unknown. The aim of the study was to assess the impact of right ventricular dysfunction on clinical outcome in patients with ischemic cardiomyopathy undergoing coronary artery bypass grafting with or without surgical ventricular reconstruction.

Methods: Of 1000 patients in the Surgical Treatment for Ischemic Heart Failure with coronary artery disease, left ventricular ejection fraction $35 \%$ or less, and anterior dysfunction, who were randomized to undergo coronary artery bypass grafting or coronary artery bypass grafting + surgical ventricular reconstruction, baseline right ventricular function could be assessed by echocardiography in 866 patients. Patients were followed for a median of 48 months. All-cause mortality or cardiovascular hospitalization was the primary end point, and all-cause mortality alone was a secondary end point.

Results: Right ventricular dysfunction was mild in 102 patients (12\%) and moderate or severe in 78 patients $(9 \%)$. Moderate to severe right ventricular dysfunction was associated with a larger left ventricle, lower ejection fraction, more severe mitral regurgitation, higher filling pressure, and higher pulmonary artery systolic pressure (all $P<.0001$ ) compared with normal or mildly reduced right ventricular function. A significant interaction between right ventricular dysfunction and treatment allocation was observed. Patients with moderate or severe right ventricular dysfunction who received coronary artery bypass grafting + surgical ventricular reconstruction had significantly worse outcomes compared with patients who received coronary artery bypass grafting alone on both the primary (hazard ratio, 1.86; confidence interval, 1.06-3.26; $P=.028$ ) and the secondary (hazard ratio, 3.37; confidence interval, 1.36-8.37; $P=.005)$ end points. After adjusting for all other prognostic clinical factors, the interaction remained significant with respect to all-cause mortality $(P=.022)$.

Conclusions: Adding surgical ventricular reconstruction to coronary artery bypass grafting may worsen long-term survival in patients with ischemic cardiomyopathy with moderate to severe right ventricular dysfunction, which reflects advanced left ventricular remodeling. (J Thorac Cardiovasc Surg 2015;149:1312-21)

See related commentary pages 1322-3.

From the Department of Cardiology, ${ }^{\text {a }}$ Congenital Heart Diseases and Electrotherapy, $\mathrm{Si}$ lesian Center for Heart Disease, Medical University of Silesia, Zabrze, Poland; Duke Clinical Research Institute, ${ }^{\mathrm{b}}$ Durham, NC; Departments of Medicine-Cardiology ${ }^{\mathrm{c}}$ and Biostatistics and Bioinformatics, ${ }^{\mathrm{d}}$ Duke University School of Medicine, Durham, NC; Department of Medicine, ${ }^{e}$ Montreal Heart Institute, University of Montreal, Montreal, Canada; Dedinje Cardiovascular Institute, ${ }^{\mathrm{f}}$ Belgrade, Serbia; Westchester Medical Center, ${ }^{\mathrm{g}}$ New York, NY; University of Ottawa Heart Institute, ${ }^{\mathrm{h}}$ Ottawa, Canada; Glasgow Royal Infirmary, ${ }^{\mathrm{i}}$ Glasgow, United Kingdom; Division of Cardiovascular Diseases, ${ }^{j}$ Mayo Clinic, Rochester, Minn; Research Institute of Circulation Pathology, ${ }^{\mathrm{k}}$ Novosibirsk, Russia; Medical University of Silesia, ${ }^{1}$ Katowice, Poland; Casa De Galicia, ${ }^{\mathrm{m}}$ Montevideo, Uruguay; Medical University of Gdansk, ${ }^{\mathrm{n}}$ Gdansk, Poland; and Ospedali Riuniti Di Bergamo, ${ }^{\circ}$ Bergamo, Italy.

The Surgical Treatment for Ischemic Heart Failure trial was supported by grants from the National Heart, Lung, and Blood Institute, National Institutes of Health (Bethesda, Md): U01HL69015, U01HL69013, and U01HL69010.
In patients with heart failure (HF), right ventricular (RV) systolic dysfunction has been associated with decreased exercise capacity $^{1,2}$ and a poor clinical outcome ${ }^{3-7}$ when compared

Disclosures: Normand Racine reports lecture fees from Servier. Eric J. Velazquez reports consulting fees from Novartis and grant support from Ikaria Pharmaceuticals. Kerry L. Lee reports consulting fees from Medtronic, Cameron Health, PPD, and CV Research foundation. Jean L. Rouleau reports consulting fees from Novartis. All other authors have nothing to disclose with regard to commercial support.

Received for publication June 16, 2014; revisions received Sept 3, 2014; accepted for publication Sept 28, 2014; available ahead of print Nov 6, 2014.

Address for reprints: Tomasz Kukulski, MD, PhD, Department of Cardiology,

Congenital Heart Diseases and Electrotherapy, Silesian Center for Heart Disease,

Medical University of Silesia, 41-800 Zabrze, ul. C. Sklodowskiej 9, Poland

(E-mail: tomasz.kukulski@sccs.pl).

$0022-5223 / \$ 36.00$

Copyright (c) 2015 by The American Association for Thoracic Surgery

http://dx.doi.org/10.1016/j.jtcvs.2014.09.117 


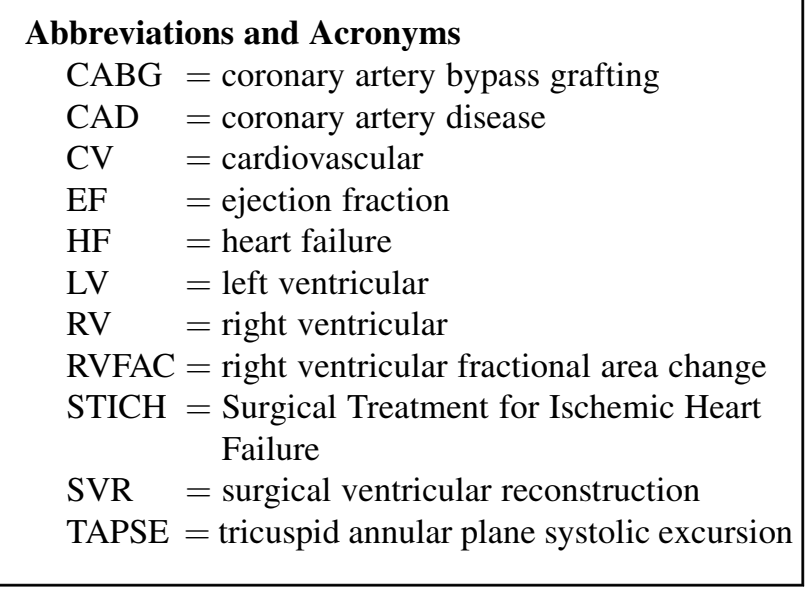

with patients who have preserved RV function. However, the small numbers of patients described in previous studies of RV dysfunction severely limit an assessment of the prevalence of $\mathrm{RV}$ dysfunction in patients with HF. Moreover, the clinical implications of RV dysfunction in patients with ischemic cardiomyopathy who undergo coronary artery bypass grafting (CABG) with or without surgical ventricular reconstruction (SVR) have not been clearly defined. The Surgical Treatment for Ischemic Heart Failure (STICH) trial $^{8}$ provides a unique opportunity to assess the importance of RV dysfunction in this clinical situation. In the STICH trial, the Echocardiography Core Laboratory (Mayo Clinic, Rochester, Minn) provided a baseline echocardiographic evaluation of structural, functional, and hemodynamic parameters of both the left and right ventricles. The STICH trial tested 2 clinically unresolved and relevant hypotheses in patients with coronary artery disease (CAD) and reduced left ventricular (LV) ejection fraction (EF). The SVR hypothesis (Hypothesis 2) of STICH randomized 1000 patients with anteroapical dysfunction to CABG with SVR versus CABG alone to test the hypothesis that in patients with LV EF $35 \%$ or less, CAD amenable to $\mathrm{CABG}$, and anterior $\mathrm{LV}$ dysfunction, the addition of SVR improves survival free of subsequent hospitalization for cardiac cause in comparison with CABG alone. ${ }^{8}$ The concept and technique of surgical ventricular restoration have been well described by Dor and colleagues. ${ }^{9}$ The primary outcome of this population has been reported by Jones and colleagues, ${ }^{10}$ and the description of clinical characteristics has been reported by Zembala and colleagues. ${ }^{11} \mathrm{~Pa}$ tients randomized to Hypothesis 2 were followed for a median of 48 months. Only 4 of the 1000 patients withdrew consent for follow-up, and 6 patients were lost to follow-up.

The present study sought to examine the prevalence of RV dysfunction in those 1000 patients to determine the relationship between RV dysfunction and other parameters of cardiac structure and function measured by echocardiography. We also examined the interaction of RV dysfunction with treatment on short- and long-term survival in these patients.

\section{MATERIALS AND METHODS}

\section{Study Population and Patient Selection}

Among the 2136 patients enrolled in the STICH trial with an LV EF $35 \%$ or less and CAD amenable to CABG, 1000 patients with anteroapical dysfunction for whom adding an SVR operation to CABG was reasonable but not required were randomized to $\mathrm{CABG}$ versus $\mathrm{CABG}+\mathrm{SVR}$. Of the 1000 patients enrolled, 866 had a baseline echocardiogram rated as fair to excellent quality (excellent for textbook quality, good for clear definition of $\mathrm{RV}$ walls from multiple views, and fair for good definition of RV walls from limited views) for qualitative assessment of RV function by the Echocardiography Core Laboratory (Figure 1).

\section{Echocardiography Study}

Baseline echocardiography was obtained within 3 months before enrollment by clinical sites and sent to the Echocardiography Core Laboratory, where each study was initially analyzed by a research sonographer blinded to randomized treatment assignment and clinical outcomes using American Society of Echocardiography guidelines ${ }^{12}$ and with a second over-read by a physician. Details of the methodology used for echocardiographic analysis have been published. ${ }^{13}$

\section{Right Ventricular Function Assessment}

$\mathrm{RV}$ function was assessed prospectively by visual interpretation and categorized as normal, mild, moderate, or severe dysfunction. The appreciation of the overall mechanical function of the RV was mainly based on the extent of RV free wall segmental motion, wall thickening, RV cavity size, and subjective assessment of RV area change (normal $>50 \%$, mild $30 \%-50 \%$, moderate $20 \%-30 \%$, and severe $<20 \%$ from diastole to systole). RV assessment was derived from the parasternal long-axis, apical 4-chamber, and subcostal views. This assessment was based on visual assessment by an experienced Echocardiography Core Laboratory physician. ${ }^{14}$

Once the results of the impact of RV function by visual assessment were known, 40 patients in each group (normal, mild, and moderate dysfunction) and all 21 patients with severe RV dysfunction were sent for blinded post hoc calculation of RV fractional area change (RVFAC). RVFAC was calculated from apical 4-chamber views as ([RV end-diastolic area - RV end-systolic area]/RV end-diastolic area) by a research sonographer with no knowledge of the patients' clinical or other echocardiography data.

\section{Statistics}

Clinical and echocardiographic characteristics were described using means and standard deviations for continuous variables and frequencies and percentages for categoric variables. Because of the limited number of patients with moderate and severe RV dysfunction, these 2 groups have been combined and analyzed as 1 moderate/severe subgroup. Comparisons of patients across 3 different levels of RV dysfunction (ie, normal, mild, or moderate/severe) were performed using KruskalWallis nonparametric analysis of variance on continuous and ordinal variables. Group comparisons of nominal categoric variables were performed using the conventional chi-square test or Fisher exact test. The prognostic effect of RV dysfunction on the short-term end point of death within 30 days after surgery was tested using the logistic regression model. The effects of the 3 levels of RV dysfunction on the long-term end points of (a) death or cardiovascular (CV) hospitalization and (b) all-cause mortality and relative risks were assessed using the Cox regression model. Event-rate estimates in each RV dysfunction group for each long-term end point were calculated using the Kaplan-Meier method. The logistic regression model and Cox regression model were also used to assess the interaction of RV dysfunction and treatment (CABG vs CABG + SVR). Testing of the independent prognostic effect of RV dysfunction and testing of the interactive effect of RV dysfunction and treatment were performed after adjusting for LV EF and other key prognostic factors identified from previous modeling analyses of the STICH SVR hypothesis patient data. 

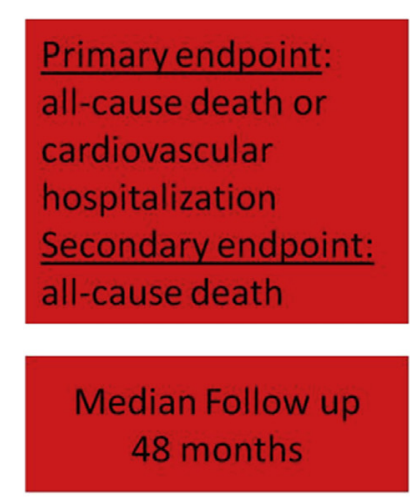

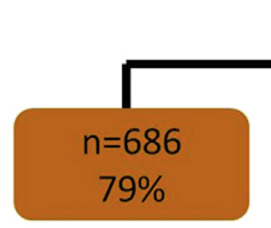

No

$\mathrm{RV}$ dysfunction

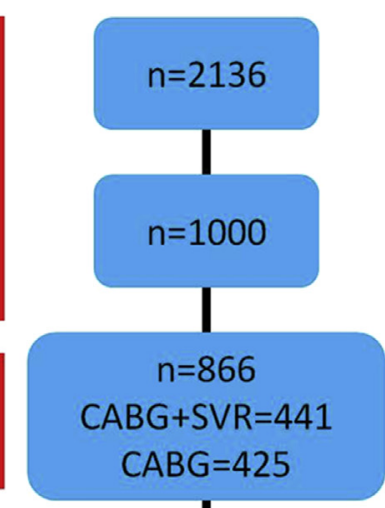

All STICH pts

Hypothesis 2 pts

$\mathrm{CABG}$ vs. $\mathrm{CABG}+\mathrm{SVR}$

Patients with available

RV echo data

FIGURE 1. Chart illustrating the design of STICH patient selection for RV function analysis. $C A B G$, Coronary artery bypass grafting; $R V$, right ventricular; $S T I C H$, Surgical Treatment for Ischemic Heart Failure; SVR, surgical ventricular reconstruction.

\section{RESULTS}

\section{Patients}

The study patients $(\mathrm{n}=866)$ consisted of 739 men $(85 \%)$ and 127 women $(15 \%)$ with a mean age of $62 \pm 10$ years randomized to CABG alone $(n=425)$ and to $\mathrm{CABG}+$ SVR $(\mathrm{n}=441)$ (Figure 1). At baseline, patients with moderate to severe RV dysfunction had more advanced HF, had a higher percentage with atrial fibrillation, had a lower percentage with prior myocardial infarction, had higher levels of creatinine and blood urea nitrogen, required more diuretic therapy, and walked shorter distances in the 6-minute walk test (Table 1).

TABLE 1. Baseline clinical characteristics of the analyzed cohort of patients $(\mathrm{N}=866)$ categorized by right ventricular dysfunction status

\begin{tabular}{|c|c|c|c|c|c|}
\hline Clinical and laboratory variables & $\begin{array}{c}\text { Total cohort } \\
\mathbf{N}=866\end{array}$ & $\begin{array}{c}\text { No } R V \text { dysfunction } \\
\quad N=686\end{array}$ & $\begin{array}{l}\text { Mild RV dysfunction } \\
\qquad \mathbf{N}=102\end{array}$ & $\begin{array}{c}\text { Moderate/severe RV } \\
\text { dysfunction } N=78\end{array}$ & $P$ value* \\
\hline Age, y & $61.6 \pm 9.8$ & $61.9 \pm 9.7$ & $60.2 \pm 10.2$ & $60.7 \pm 10.6$ & .246 \\
\hline BMI, $\mathrm{kg} / \mathrm{m}^{2}$ & $27.4 \pm 4.4$ & $27.6 \pm 4.3$ & $27.2 \pm 4.9$ & $26.6 \pm 5.2$ & .159 \\
\hline Diabetes $(\%)$ & $289(33.4)$ & $218(31.8)$ & $41(40.2)$ & $30(38.5)$ & .148 \\
\hline Chronic renal insufficiency, n (\%) & $73(8.4)$ & $53(7.7)$ & $10(9.8)$ & $10(12.8)$ & .270 \\
\hline Hypertension, n (\%) & $502(58.0)$ & $402(58.6)$ & $59(57.8)$ & $41(52.6)$ & .592 \\
\hline Atrial fibrillation, $\mathrm{n}(\%)$ & $98(11.3)$ & $65(9.5)$ & $17(16.7)$ & $16(20.5)$ & .003 \\
\hline Prior MI, n (\%) & $754(87.1)$ & $611(89.1)$ & $87(85.3)$ & $56(71.8)$ & $\leq .001$ \\
\hline Diuretics (loop/thiazide), n (\%) & $511(59.0)$ & $382(55.7)$ & $65(63.7)$ & $64(82.1)$ & $\leq .001$ \\
\hline Diuretics $\left(\mathrm{K}^{+}\right.$sparing), $\mathrm{n}(\%)$ & $325(37.5)$ & $236(34.4)$ & $48(47.1)$ & $41(52.6)$ & .001 \\
\hline Statin, n (\%) & $668(77.1)$ & $544(79.3)$ & 73 (71.6) & $51(65.4)$ & .008 \\
\hline Beta-blocker, n (\%) & $745(86.0)$ & $603(87.9)$ & $77(75.5)$ & $65(83.3)$ & .003 \\
\hline Aspirin, n (\%) & $663(76.6)$ & $540(78.7)$ & $68(66.7)$ & $55(70.5)$ & .012 \\
\hline Creatinine (mg/dL) & $1.1 \pm 0.4$ & $1.1 \pm 0.3$ & $1.2 \pm 0.7$ & $1.3 \pm 0.5$ & .001 \\
\hline BUN (mg/dL) & $28.6 \pm 20.1$ & $26.7 \pm 16.5$ & $31.6 \pm 27.0$ & $38.8 \pm 29.7$ & .001 \\
\hline Systolic BP (mm Hg) & $120.7 \pm 17.7$ & $121.7 \pm 17.7$ & $117.9 \pm 17.0$ & $115.1 \pm 16.8$ & .001 \\
\hline NYHA class III, n (\%) & $373(43.1)$ & $282(41.1)$ & $51(50.0)$ & $40(51.3)$ & $\leq .001$ \\
\hline NYHA class IV, n (\%) & $46(5.3)$ & $26(3.8)$ & $4(3.9)$ & $16(20.5)$ & $\leq .001$ \\
\hline Heart rate (beats/min) & $72.5 \pm 13.3$ & $71.6 \pm 12.9$ & $75.8 \pm 16.2$ & $75.8 \pm 11.7$ & $\leq .001$ \\
\hline 6-min walk distance $(\mathrm{m})$ & $347.2 \pm 120.5$ & $351.8 \pm 116.5$ & $355.8 \pm 124.9$ & $285.4 \pm 137.2$ & .001 \\
\hline
\end{tabular}

$B M I$, Body mass index; $B P$, blood pressure; $B U N$, blood urea nitrogen; $M I$, myocardial infarction; $N Y H A$, New York Heart Association; $R V$, right ventricular. *P value differences between RV dysfunction groups. 
TABLE 2. Baseline echocardiographic characteristics of the analyzed cohort of patients $(N=866)$ categorized by right ventricular dysfunction status

\begin{tabular}{|c|c|c|c|c|c|}
\hline Echocardiography variables & $\begin{array}{c}\text { Total cohort } \\
\mathbf{N}=\mathbf{8 6 6} \\
\end{array}$ & $\begin{array}{c}\text { No RV dysfunction } \\
\qquad N=686 \\
\end{array}$ & $\begin{array}{l}\text { Mild RV dysfunction } \\
\qquad \mathrm{N}=102 \\
\end{array}$ & $\begin{array}{r}\text { Moderate/severe RV } \\
\text { dysfunction } \mathrm{N}=78\end{array}$ & $P$ value* \\
\hline LVEDV (mL) & $225 \pm 69$ & $220 \pm 68$ & $234 \pm 69$ & $256 \pm 68$ & $<.001$ \\
\hline LVESV (mL) & $161 \pm 60$ & $155 \pm 58$ & $172 \pm 60$ & $199 \pm 61$ & $<.001$ \\
\hline LVED index (mL/BSA) & $117 \pm 35$ & $114 \pm 34$ & $123 \pm 32$ & $137 \pm 40$ & $<.0001$ \\
\hline LVES index (mL/BSA) & $84 \pm 31$ & $80 \pm 30$ & $90 \pm 29$ & $107 \pm 35$ & $<.0001$ \\
\hline $\mathrm{EF}(\%)$ & $29 \pm 8$ & $30 \pm 7$ & $27 \pm 7$ & $22 \pm 6$ & $<.0001$ \\
\hline Sphericity index & $1.49 \pm 0.19$ & $1.50 \pm 0.19$ & $1.47 \pm 0.18$ & $1.45 \pm 0.16$ & .063 \\
\hline Global hypokinesis, n (\%) & $84(9.7)$ & $62(9.1)$ & $12(11.8)$ & $10(12.8)$ & .433 \\
\hline Wall motion score index & $2.22 \pm 0.33$ & $2.18 \pm 0.33$ & $2.32 \pm 0.30$ & $2.44 \pm 0.24$ & $<.001$ \\
\hline Inferior basal WMSI & $2.08 \pm 0.80$ & $2.02 \pm 0.81$ & $2.21 \pm 0.75$ & $2.43 \pm 0.70$ & $<.001$ \\
\hline Apical WMSI & $2.87 \pm 0.45$ & $2.88 \pm 0.46$ & $2.85 \pm 0.34$ & $2.90 \pm 0.42$ & .489 \\
\hline E DT (ms) & $184 \pm 54$ & $192 \pm 53$ & $161 \pm 45$ & $140 \pm 40$ & $<.001$ \\
\hline $\mathrm{E} / \mathrm{A}$ & $1.33 \pm 0.91$ & $1.17 \pm 0.75$ & $1.82 \pm 1.08$ & $2.36 \pm 1.28$ & $<.001$ \\
\hline $\mathrm{E} / \mathrm{E}^{\prime}$ septal & $17 \pm 9$ & $16 \pm 8$ & $21 \pm 10$ & $27 \pm 17$ & $<.001$ \\
\hline $\mathrm{E} / \mathrm{E}^{\prime}$ lateral & $14 \pm 10$ & $13 \pm 8$ & $16 \pm 11$ & $20 \pm 21$ & .059 \\
\hline Diastolic filling pattern & $2.91 \pm 0.77$ & $2.80 \pm 0.74$ & $3.4 \pm 0.78$ & $3.46 \pm 0.79$ & $<.001$ \\
\hline MR severity & $1.11 \pm 0.95$ & $0.99 \pm 0.85$ & $1.38 \pm 1.03$ & $1.85 \pm 1.22$ & $<.001$ \\
\hline LA volume (mL) & $82 \pm 29$ & $78 \pm 27$ & $89 \pm 30$ & $101 \pm 30$ & $<.001$ \\
\hline TR velocity $(\mathrm{m} / \mathrm{s})$ & $2.83 \pm 0.55$ & $2.73 \pm 0.50$ & $2.97 \pm 0.57$ & $3.12 \pm 0.63$ & $<.001$ \\
\hline PASP (mm Hg) & $42 \pm 15$ & $39 \pm 14$ & $45 \pm 14$ & $52 \pm 16$ & $<.001$ \\
\hline Stroke volume $(\mathrm{mL})$ & $66 \pm 19$ & $68 \pm 18$ & $61 \pm 20$ & $53 \pm 17$ & $<.01$ \\
\hline Cardiac output (mL) & $4519 \pm 1384$ & $4634 \pm 1399$ & $4236 \pm 1227$ & $3699 \pm 1115$ & $<.01$ \\
\hline Cardiac index $(\mathrm{mL})$ & $2334 \pm 708$ & $2382 \pm 722$ & $2253 \pm 602$ & $1924 \pm 563$ & $\leq .001$ \\
\hline
\end{tabular}

$B S A$, Body surface area; $D T$, deceleration time; $E$, early diastolic velocity; $E / A$, early/late velocity ratio; $E / E^{\prime}$, early mitral/annular velocity ratio; $E F$, ejection fraction; $L A$, left atrial; $L V E D$, left ventricular end-diastolic; $L V E D V$, left ventricular end-diastolic volume; $L V E S$, left ventricular end-systolic; $L V E S V$, left ventricular end-systolic volume; $M R$, mitral regurgitation; $P A S P$, pulmonary artery systolic pressure; $R V$, right ventricular; $T R$, tricuspid regurgitation; $W M S I$, wall motion score index. $* P$ value differences between $\mathrm{RV}$ dysfunction groups.

\section{Prevalence of Right Ventricular Dysfunction and Its Association}

RV function was normal in 686 patients (79\%), mildly reduced in 102 patients $(12 \%)$, and moderately to severely reduced in 78 patients $(9 \%)$ (Figure 1). Of the patients sent for post hoc analyses of RVFAC, measurements could be performed reliably in only 20 normal patients, 25 patients with mild RV dysfunction, 22 patients with moderate RV dysfunction, and 16 patients with severe dysfunction. RVFAC was $50.1 \% \pm 9.1 \%, 34.6 \% \pm 5.5 \%, 27.5 \% \pm$ $4.9 \%$, and $17.6 \% \pm 3.7 \%$, respectively $(P<.001)$. Two-dimensional, Doppler, and tissue Doppler echocardiography data in the 3 groups of patients defined by RV function as (1) normal, (2) mild, and (3) moderate to severe dysfunction are shown in Table 2. Both LVend-diastolic and LV end-systolic volumes increased progressively with increasing RV dysfunction (Table 2 and Figure 2). In parallel, LV EF was progressively reduced with worsening of RV dysfunction. All LV diastolic function and filling parameters (E/A ratio, deceleration time, E/e, and left atrial volume index) were progressively worse with more severe RV dysfunction, indicating higher LV filling pressure with worsening RV dysfunction. Mitral regurgitation was more severe and Doppler-derived pulmonary artery systolic pressure was higher in patients with moderate to severe
RV dysfunction compared with the patients with normal RV function or mild dysfunction (Table 2 and Figure 3).

\section{Prognostic Role of Right Ventricular Dysfunction}

The prognostic effect of RV dysfunction (independent of treatment) was significant for the short-term outcome of 30-day mortality $(P=.023)$ and the long-term outcome of death or $\mathrm{CV}$ hospitalization $(P=.022)$. The relationship with long-term mortality did not achieve conventional significance $(P=.070)$ (Table 3$)$. The nature of these relationships is illustrated with Kaplan-Meier estimates of event rates by degree of RV dysfunction (Figure 3), where the highest event rates (worst outcomes) are observed in the patients with moderate to severe RV dysfunction. However, the relationship of $\mathrm{RV}$ dysfunction with each of the clinical outcomes considered was no longer significant after adjusting for LV EF and even less so after adjusting for LV EF plus the other prognostic clinical and echocardiographic factors (Table 3 ).

Impact of Right Ventricular Dysfunction on the Treatment Effect of Coronary Artery Bypass Grafting Versus Coronary Artery Bypass Grafting + Surgical Ventricular Reconstruction

For patients with normal or mildly reduced RV function, the outcomes of CABG alone compared with 


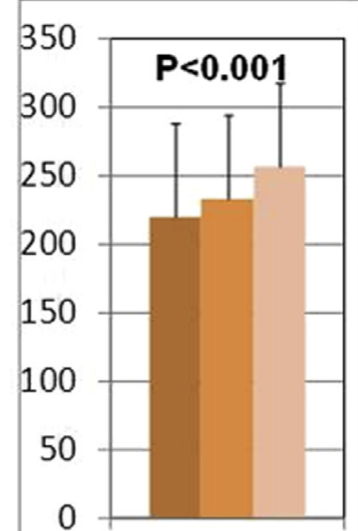

A
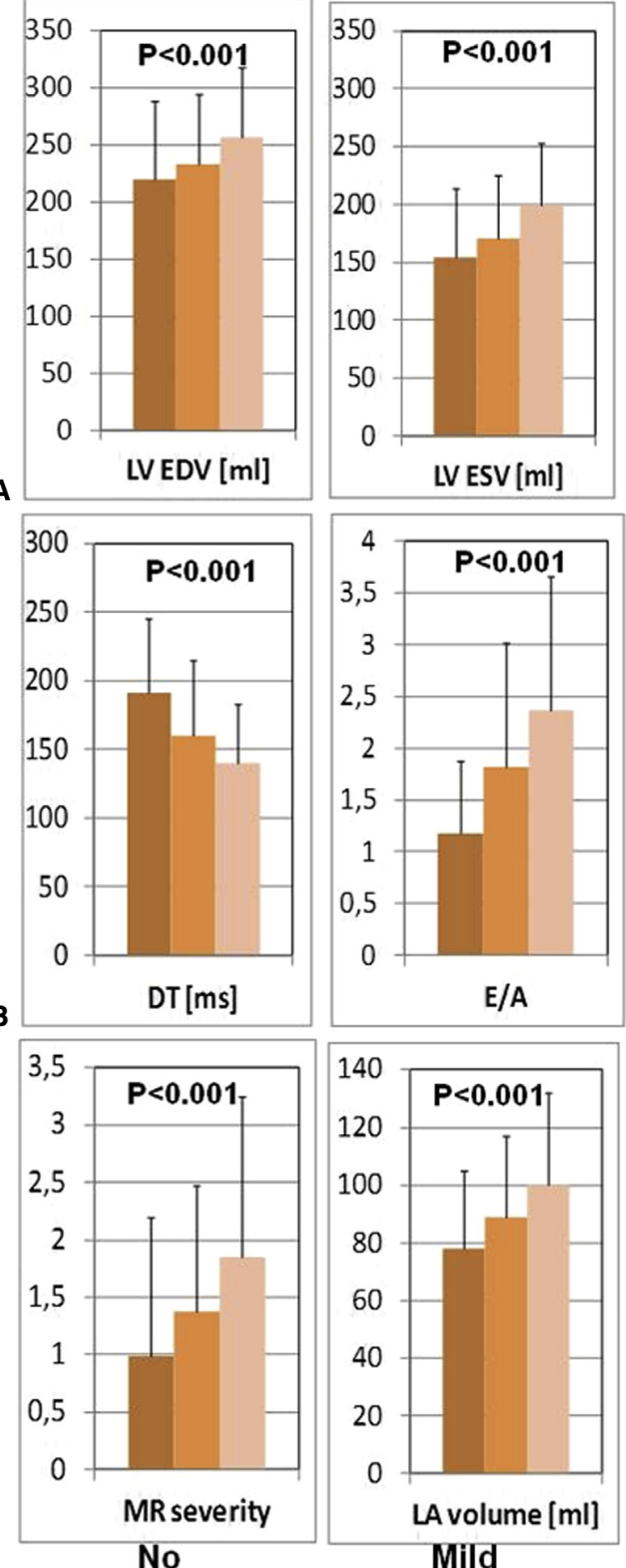

RV dysfunction
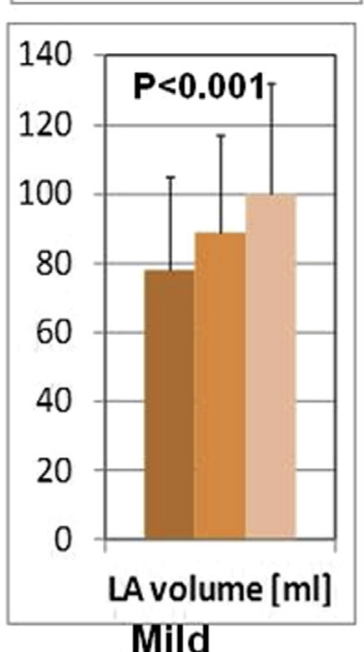

RV dysfunction
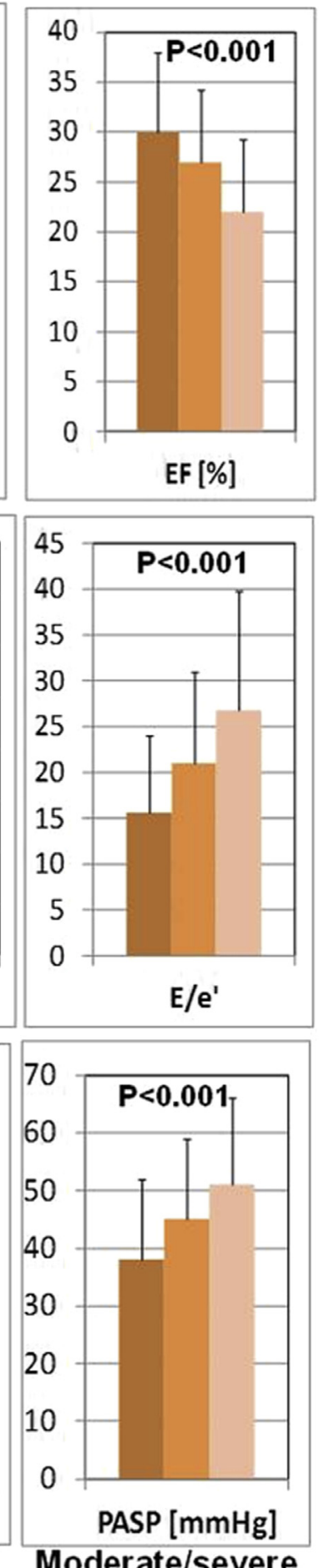

Moderate/severe

RV dysfunction

FIGURE 2. Associations between degree of RV dysfunction. A, LV remodeling expressed by LV EDV, ESV, and EF. B, LV diastolic properties represented by DT, E/A, and E/e'. C, Left atrial remodeling expressed by MR severity, left atrial volume, and pulmonary artery systolic pressure (all differences among RV dysfunction subgroups are significant, nonparametric Kruskal-Wallis test). DT, Deceleration time; $E F$, ejection fraction; $L A$, left atrial; $L V E D V$, left ventricular end-diastolic volume; $L V E S V$, left ventricular end-systolic volume; $M R$, mitral regurgitation; $P A S P$, pulmonary artery systolic pressure; $R V$, right ventricular. $E / A$, early/late velocity ratio; $E / e^{\prime}$, early mitral flow/early annular velocity ratio. 

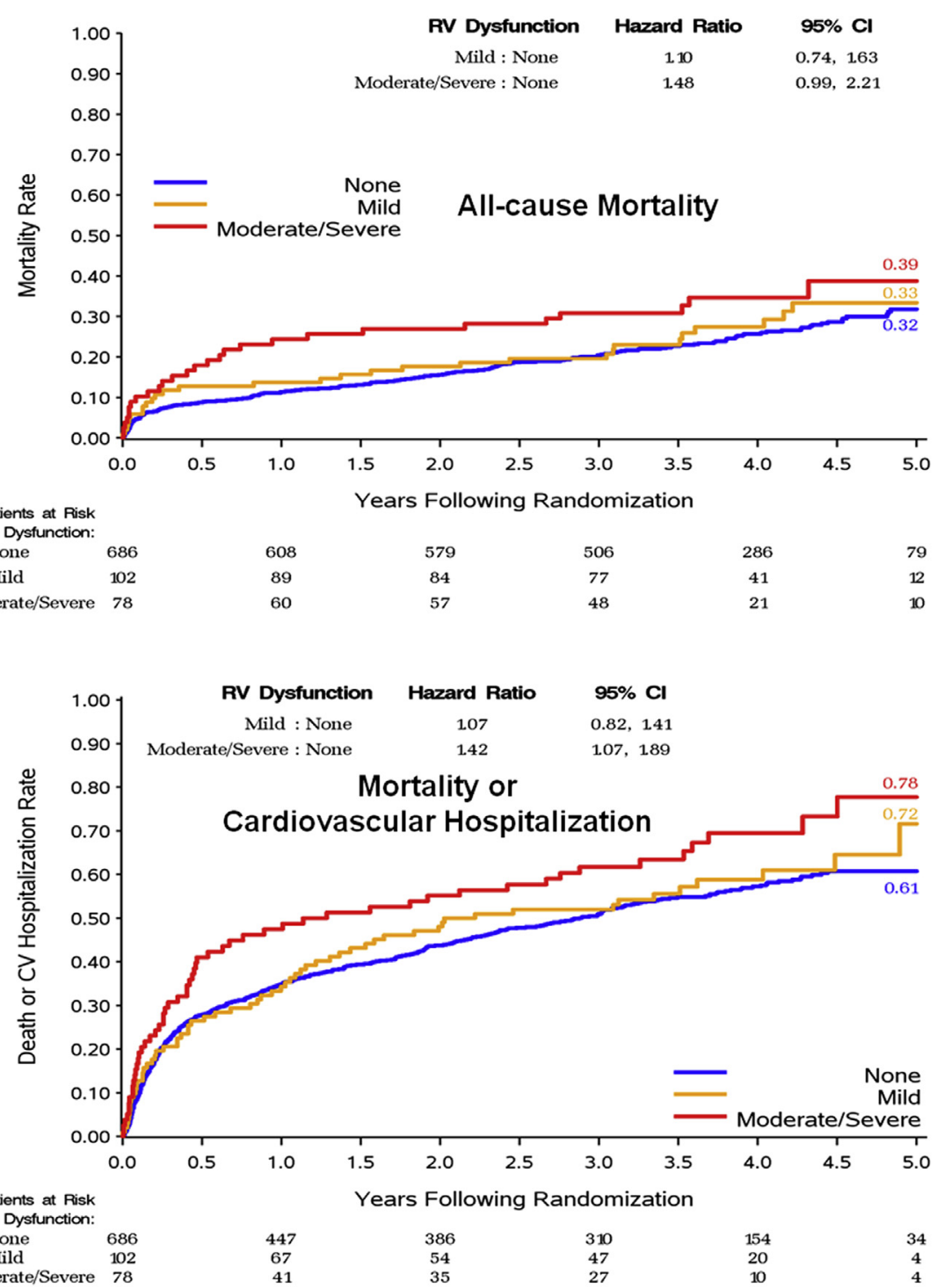

FIGURE 3. Impact of the coexisting RV dysfunction on long-term outcome in the analyzed cohort of STICH patients ( $\mathrm{n}=866)$. Kaplan-Meier estimates of event rate by $\mathrm{RV}$ dysfunction status. $C I$, Confidence interval; $R V$, right ventricular; $C V$, cardiovascular.

CABG + SVR were not significantly different for the primary (death or $\mathrm{CV}$ hospitalization) or the secondary (death) end points (Figure 4, $A$ and $B$ ). However, when RV function was moderately or severely reduced, there were significantly higher event rates for CABG + SVR compared with $\mathrm{CABG}$ alone for death or $\mathrm{CV}$ hospitalization $(P=.028)$ and for death alone $(P=.005)$ (Figure $4, A$ and $B)$. There was a statistically significant interaction between RV dysfunction and treatment for the composite end point of death or CV hospitalization $(P=.013)$ and for death alone $(P=.001)$ because of the markedly higher incidence of clinical outcomes among the patients with moderate/severe RV dysfunction who underwent CABG + SVR. For the death end point, the interaction remained significant even after adjusting for all the other prognostic factors $(P=.022)$ (Table 3). There also was a worsening trend for CABG +
SVR with respect to the short-term outcome of surgical death (30-day mortality). Thirty-day mortality among patients with moderately or severely reduced RV function was $5.9 \%$ in CABG alone and $13.6 \%$ in CABG + SVR, whereas the corresponding 30-day mortality rates among patients with no or mild RV dysfunction were $5.0 \%$ for CABG and $4.7 \%$ for $\mathrm{CABG}+\mathrm{SVR}$.

\section{DISCUSSION}

Prevalence of Right Ventricular Dysfunction and Its Association With Left Ventricular Remodeling in Ischemic Cardiomyopathy

This is the largest study to evaluate the prevalence and determinants of RV dysfunction in patients with ischemic cardiomyopathy. In the STICH population, $21 \%$ of patients had some degree of RV dysfunction and $9 \%$ had moderate 
TABLE 3. Prognostic significance of right ventricular dysfunction and the interactive effect of right ventricular dysfunction and treatment: Univariate and multivariable assessments

\begin{tabular}{|c|c|c|c|c|c|c|}
\hline \multirow[b]{2}{*}{ End points } & \multicolumn{3}{|c|}{ Main effect of RV dysfunction } & \multicolumn{3}{|c|}{ Interaction of RV dysfunction and treatment } \\
\hline & Nonadjusted & $\begin{array}{l}\text { Adjusted } \\
\text { for LV EF }\end{array}$ & $\begin{array}{c}\text { Adjusted for all } \\
\text { prognostic clinical and } \\
\text { echocardiography } \\
\text { factors* }\end{array}$ & Nonadjusted & $\begin{array}{l}\text { Adjusted } \\
\text { for LV EF }\end{array}$ & $\begin{array}{c}\text { Adjusted for all } \\
\text { prognostic clinical and } \\
\text { echocardiography } \\
\text { factors* }\end{array}$ \\
\hline $\begin{array}{l}\text { Death within } 30 \mathrm{~d} \text { after surgery } \dagger \\
\quad(\mathrm{N}=848 \text {, events }=45)\end{array}$ & 0.023 & 0.164 & 0.672 & 0.096 & 0.152 & 0.131 \\
\hline $\begin{array}{l}\text { All-cause death }(\mathrm{N}=866 \\
\text { events }=239)\end{array}$ & 0.070 & 0.632 & 0.711 & 0.001 & 0.007 & 0.022 \\
\hline $\begin{array}{c}\text { Death or CV hospitalization } \\
(\mathrm{N}=866, \text { events }=506)\end{array}$ & 0.022 & 0.281 & 0.838 & 0.013 & 0.041 & 0.302 \\
\hline
\end{tabular}

Bold indicates $P<.05$. $C V$, Cardiovascular; $E F$, ejection fraction; $L V$, left ventricular; $R V$, right ventricular. *Prognostic factors identified from previous modeling analyses were used as adjustment variables for the 3 different end points. Atrial flutter/fibrillation, age, mitral regurgitation, creatinine, hemoglobin, end-systolic volume index, and LV EF were included in the adjustment for all 3 end points. In addition to the factors listed, previous myocardial infarction, previous stroke, and New York Heart Association HF class were included for both the death end point and the death or CV hospitalization end point. Canadian Cardiovascular Society angina class was also included in the model for death within 30 days after surgery. Diabetes and hyperlipidemia were also included in the death model. The ability to perform the 6-minute walk test was also included in the death or cardiovascular end point model. †Only patients who actually underwent surgery are included in the analysis of deaths within 30 days after surgery.

or severe dysfunction. Progressively more advanced LV remodeling (larger $\mathrm{LV}$ volumes, lower $\mathrm{EF}$, and more severe mitral regurgitation) and worse LV hemodynamic profiles were associated with increasing RV dysfunction. LV systolic and diastolic function parameters, as well as severity of mitral regurgitation, were progressively worse with increasing severity of RV systolic dysfunction.

\section{Mechanisms of Right Ventricular Dysfunction in Ischemic Cardiomyopathy}

Several potential underlying mechanisms may explain why progressive $\mathrm{RV}$ dysfunction is often accompanied by increasing LV dysfunction. ${ }^{15} \mathrm{RV}$ dysfunction may reflect primary LV, left atrial, or mitral valve pathology ${ }^{16,17}$ mediated through direct $\mathrm{RV}$ compression and the mechanism of RV/LV interdependence or through increased pulmonary pressures and RV afterload due to LV dysfunction. ${ }^{18,19}$ Alternatively, both ventricles might be affected by the same underlying pathologic process (CAD).$^{20}$ However, the fact that pulmonary artery systolic pressure was found to increase progressively with worsening of RV systolic function suggests that RV dysfunction is related to functional and hemodynamic abnormalities of the LV. This notion is also supported by a recent study of Verhaert and colleagues. ${ }^{21}$ Although many studies have shown that RV dysfunction is a predictor for a poor clinical outcome in patients with $\mathrm{HF}$ and reduced $\mathrm{LV} \mathrm{EF}^{22}$ our study is one of the first to demonstrate a relationship between the degree of LV remodeling and the severity of $\mathrm{RV}$ dysfunction. The $\mathrm{RV}$ is increasingly being recognized as a potential therapeutic target in patients with chronic $\mathrm{HF}^{23}$ Although not studied extensively, angiotensinconverting enzyme inhibitors ${ }^{24}$ and beta-blockers ${ }^{25}$ seem to improve RV function. Specific therapies targeted indirectly at RV dysfunction in chronic $\mathrm{HF}$ have provided disappointing results. $^{26}$ Data from Verhaert and colleagues $^{21}$ suggest that RV function may improve when $\mathrm{LV}$ abnormalities are treated.

\section{Right Ventricular Dysfunction and Surgical Ventricular Reconstruction}

The long-term outcome of the patients who received CABG + SVR in STICH was adversely affected when $\mathrm{RV}$ function was at least moderately reduced at baseline. The abrupt reduction in LV size and volume may have increased diastolic stiffness and aggravated diastolic function and filling pressure, especially when LV filling pressure was already markedly elevated at baseline in patients with RV dysfunction. Contrary to the initial belief, we have demonstrated that SVR seems to have a greater benefit in patients with an early stage of ischemic cardiomyopathy and less benefit, or even harm, in patients with a more advanced cardiomyopathy and a larger LV. ${ }^{27}$ The worse outcome of SVR in the setting of advanced RV dysfunction confirms the earlier report of worse outcome of SVR in patients with a larger LV and more reduced EF associated with RV dysfunction.

\section{Right Ventricular Function Assessment}

Many indicators of RV contractility have been proposed (RV EF, RV FAC, tricuspid annular plane systolic excursion [TAPSE], strain, strain rate, RV myocardial performance index, dP/dT max, RV wall motion analysis, tricuspid annular systolic velocity, maximal RV elastance, and Tei index ${ }^{17}$ ), but there is no recognized gold standard imaging modality or parameter for assessment of RV function. ${ }^{28-32}$ Among the numerous quantitative RV parameters studied by Verhaert and colleagues, ${ }^{21}$ only RV systolic strain was predictive of clinical outcome. de Groote and colleagues ${ }^{22}$ showed radionuclide RV EF but not TAPSE to be the 


\section{Endpoint=Death or Cardiovascular Hospitalization}
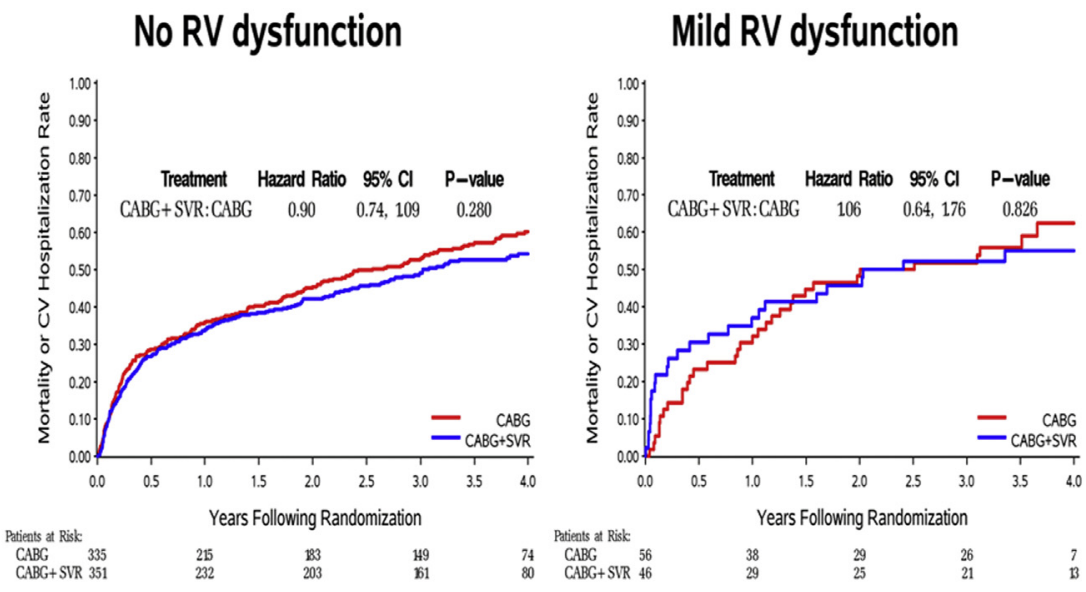

\section{Moderate/Severe RV dysfunction}

Interaction of RV Dysfunction and Treatment (CABG+SVR vs. CABG): Non-adjusted $P$-value $=0.013$

A

Adjusted P-value $=0.302$

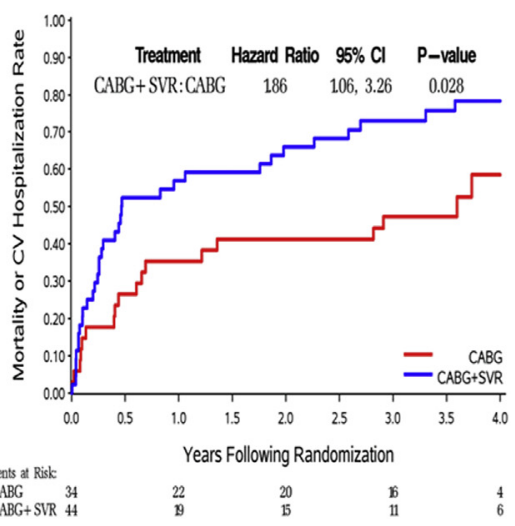

\section{Endpoint $=$ Death}
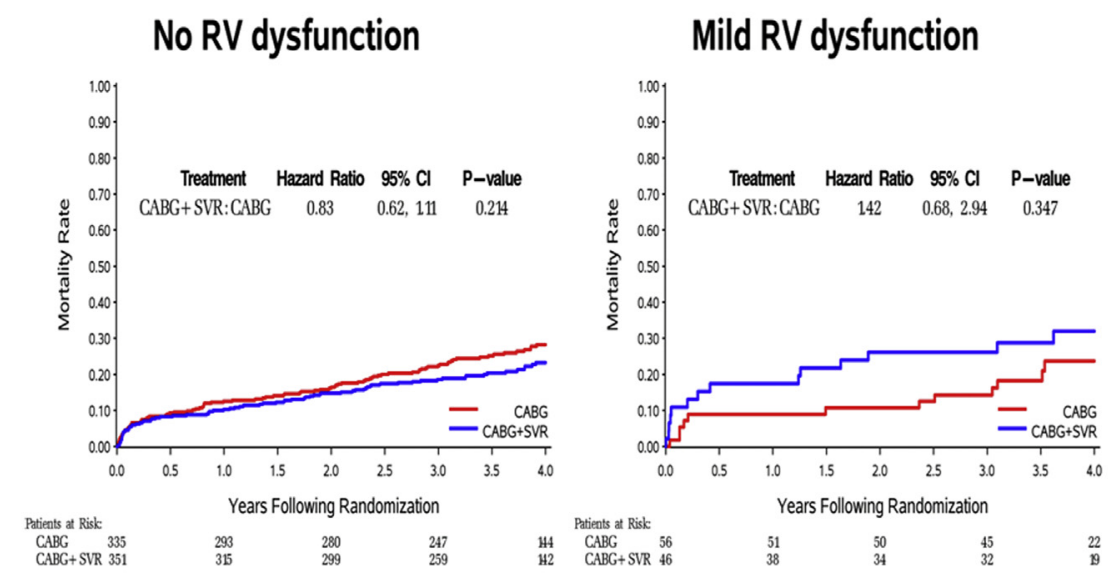

\section{Moderate/Severe RV dysfunction}

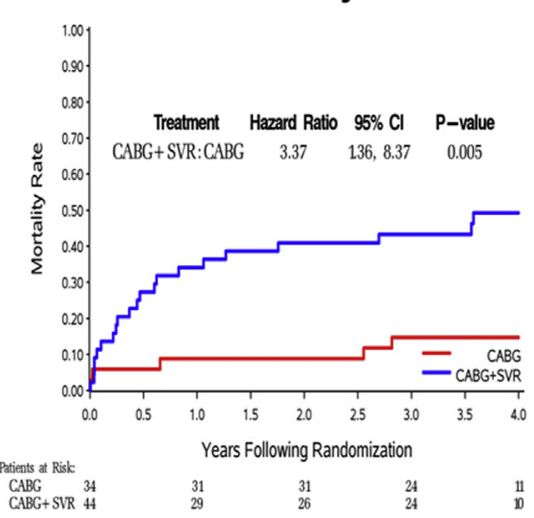

Interaction of RV Dysfunction and Treatment (CABG+SVR vs. CABG):

Non-adjusted P-value $=0.001$

\section{B}

Adjusted P-value $=\mathbf{0 . 0 2 2}$

FIGURE 4. A, Interaction of RV dysfunction and treatment allocation. Kaplan-Meier estimates of event rate by treatment group and LV dysfunction groups. B, Interaction of RV dysfunction and treatment allocation. Kaplan-Meier estimates of event rate by treatment group and LV dysfunction groups. $C A B G$, Coronary artery bypass grafting; $C I$, confidence interval; $C V$, cardiovascular; $R V$, right ventricular; $S V R$, surgical ventricular reconstruction.

independent predictor of cardiac survival. TAPSE, RV Tei index, RVFAC, and tricuspid systolic annulus velocity were not predictive of long-term outcome ${ }^{33}$; however, in the Survival And Ventricular Enlargement trial (SAVE study), RVFAC has been shown to be an independent predictor of mortality and the development of HF in patients with known LV dysfunction. ${ }^{34}$ Although the optimal method of assessment of RV function is not yet clear, ${ }^{35}$ the visually and qualitatively assessed RV function used in our study performed well as it related to outcome.

\section{Study Limitations}

In our study, moderate to severe RV dysfunction was found in only $9 \%$ of the study patients. This may underestimate the true prevalence of the degree of $\mathrm{RV}$ dysfunction because patients with significant RV 
dysfunction or pulmonary hypertension might have been excluded by study investigators or surgeons because of a perceived high risk for an operation. The evaluation of $\mathrm{RV}$ function that we used was a visual assessment. It is difficult to categorize visual assessment, and our classification may not be easily translated to other laboratories. However, differentiation of severe RV dysfunction from normal function is relatively easy by visual assessment. It is more difficult to determine mild and moderate RV dysfunction. However, we believe that our observations are clinically relevant because this visual method is the most practical technique in "real life" practice in almost all echocardiography laboratories. Although the visual assessment of RV function in our study was shown to correlate well with RVFAC, fractional area change was measured after the completion of the trial and once the study results with visual assessment were known. This limitation notwithstanding, the measurements of RVFAC were performed by blinded readers. Also, because a significant proportion of patients could not have RVFAC reliably calculated, it may be that visual assessment, the measure used in this study, is the most widely applicable technique for evaluation of RV function in the general population of patients such as those in the STICH trial.

\section{CONCLUSIONS}

In patients with ischemic cardiomyopathy, RV dysfunction is associated with more advanced LV remodeling and hemodynamic abnormalities (larger LV volumes, lower $\mathrm{EF}$, higher filling pressure, and more severe mitral regurgitation). The interaction between RV dysfunction and treatment is significant for mortality after carefully adjusting for other prognostic clinical and echocardiographic factors. When baseline RV function is moderately to severely reduced, the addition of SVR to CABG seems to worsen long-term survival compared with the use of CABG alone.

The authors thank Vanessa Moore for continuous support and invaluable assistance in preparation of this article.

\section{References}

1. Baker BJ, Wilen MM, Boyd CM, Dinh H, Franciosa JA. Relation of right ventricular ejection fraction to exercise capacity in chronic left ventricular failure. Am J Cardiol. 1984;54:596-9.

2. Di Salvo TG, Mathier M, Semigran MJ, Dec GW. Preserved right ventricular ejection fraction predicts exercise capacity and survival in advanced heart failure. J Am Coll Cardiol. 1995;25:1143-53.

3. de Groote P, Millaire A, Foucher-Hossein C, Nugue O, Marchandise X, Ducloux G, et al. Right ventricular ejection fraction is an independent predictor of survival in patients with moderate heart failure. J Am Coll Cardiol. 1998;32: 948-54.

4. Polak JF, Holman BL, Wynne J, Colucci WS. Right ventricular ejection fraction: an indicator of increased mortality in patients with congestive heart failure associated with coronary artery disease. J Am Coll Cardiol. 1983;2:217-24.

5. Gavazzi A, Berzuini C, Campana C, Inserra C, Ponzetta M, Sebastiani R, et al. Value of right ventricular ejection fraction in predicting short-term prognosis of patients with severe chronic heart failure. J Heart Lung Transplant. 1997;16: 774-85.

6. Ghio S, Gavazzi A, Campana C, Inserra C, Klersy C, Sebastiani R, et al. Independent and additive prognostic value of right ventricular systolic function and pulmonary artery pressure in patients with chronic heart failure. J Am Coll Cardiol. 2001;37:183-8.

7. Ghio S, Recusani F, Klersy C, Sebastiani R, Laudisa ML, Campana C, et al. Prognostic usefulness of the tricuspid annular plane systolic excursion in patients with congestive heart failure secondary to idiopathic or ischemic dilated cardiomyopathy. Am J Cardiol. 2000;85:837-42.

8. Velazquez EJ, Lee KL, O'Connor CM, Oh JK, Bonow RO, Pohost GM, et al. The rationale and design of the Surgical Treatment for Ischemic Heart Failure (STICH) trial. J Thorac Cardiovasc Surg. 2007;134:1540-7.

9. Dor V, DiDonato M, Sabatier M, Montiglio F, Civaia F, RESTORE Group. Left ventricular reconstruction by endoventricular circular patch plasty repair: a 17-year experience. Semin Thorac Cardiovasc Surg. 2001;13:435-47.

10. Jones RH, Velazquez EJ, Michler RE, Sopko G, Oh JK, O’Connor CM, et al. Coronary bypass surgery with or without surgical ventricular reconstruction. STICH Hypothesis 2 Investigators. N Engl J Med. 2009;360:1705-17.

11. Zembala M, Michler RE, Rynkiewicz A, Huynh T, She L, Lubiszewska B, et al. Clinical characteristics of patients undergoing surgical ventricular reconstruction by choice and by randomization. J Am Coll Cardiol. 2010;56:499-507.

12. Douglas PS, DeCara JM, Devereux RB, Duckworth S, Gardin JM, Jaber WA, et al. Echocardiographic imaging in clinical trials: American Society of Echocardiography Standards for echocardiography core laboratories: endorsed by the American College of Cardiology Foundation. J Am Soc Echocardiogr. 2009;22:755-65.

13. Oh JK, Pellikka PA, Panza JA, Biernat J, Attisano T, Manahan BG, et al. Core lab analysis of baseline echocardiographic studies in the STICH trial and recommendation for use of echocardiography in future clinical trials. $J$ Am Soc Echocardiogr. 2012;25:327-36.

14. Drake D, Gupta R, Lloyd SG, Gupta H. Right ventricular function assessment: comparison of geometric and visual method response to short-axis slice summation method. Echocardiography. 2007:24:1013-9.

15. Voelkel NF, Quaife RA, Leinwand LA, Barst RJ, McGoon MD, Meldrum DR, et al. Right ventricular function and failure. Report of a National Heart, Lung, and Blood Institute working group on cellular and molecular mechanisms of right heart failure. Circulation. 2006;114:1883-91.

16. Dini FL, Conti U, Fontanive P, Andreini D, Banti S, Braccini L, et al. Right ventricular dysfunction is a major predictor of outcome in patients with moderate to severe mitral regurgitation and left ventricular dysfunction. Am Heart J. 2007; 154:172-9.

17. Haddad F, Hunt SA, Rosenthal DN, Murphy DJ. Right ventricular function in cardiovascular disease, Part I: Anatomy, physiology, aging, and functional assessment of the right ventricle. Circulation. 2008;117:1436-48.

18. Damman K, Navis G, Smilde TD, Voors AA, van der Bij W, van Veldhuisen DJ, et al. Decreased cardiac output, venous congestion and the association with renal impairment in patients with cardiac dysfunction. Eur J Heart Fail. 2007; 9:872-8.

19. Maekawa E, Inomata T, Watanabe I. Prognostic significance of right ventricular dimension on acute decompensation in left sided heart failure. Int Heart J. 2011; 52:119-26.

20. Mishra RK, Devereux RB, Cohen BE, Whooley MA, Schiller NB. Prediction of heart failure and adverse cardiovascular events in outpatients with coronary artery disease using mitral E/A ratio in conjunction with e-wave deceleration time: the heart and soul study. J Am Soc Echocardiogr. 2011;24:1134-40.

21. Verhaert D, Mullens W, Borowski A, Popović ZB, Curtin RJ, Thomas JD, et al. Right ventricular response to intensive medical therapy in advanced decompensated heart failure. Circ Heart Fail. 2010;3:340-6.

22. de Groote P, Fertin M, Goéminne C, Petyt G, Peyrot S, Foucher-Hossein C, et al. Right ventricular systolic function for risk stratification in patients with stable left ventricular systolic dysfunction: comparison of radionuclide angiography to echo Doppler parameters. Eur Heart J. 2012;33:2672-9.

23. Gavazzi A, Ghio S, Scelsi L, Campana C, Klersy C, Serio A, et al. Response of the right ventricle to acute pulmonary vasodilatation predicts the outcome in patients with advanced heart failure and pulmonary hypertension. Am Heart J. 2003;145:310-6.

24. Packer M, Lee WH, Medina N, Yushak M. Hemodynamic and clinical significance of the pulmonary vascular response to long-term captopril therapy in patients with severe chronic heart failure. J Am Coll Cardiol. 1985; $6: 635-45$. 
25. Quaife RA, Christian PE, Gilbert EM, Datz FL, Volkman K, Bristow MR. Effects of carvedilol on right ventricular function in chronic heart failure. Am J Cardiol. 1998;81:247-50.

26. Redfield MM, Chen HH, Borlaug BA, Semigran MJ, Lee KL, Lewis G, et al. Effect of phosphodiesterase-5 inhibition on exercise capacity and clinical status in heart failure with preserved ejection fraction. RELAX Trial. JAMA. 2013;309: 1268-77.

27. Oh JK, Velazquez EJ, Menicanti L, Pohost GM, Bonow RO, Lin G, et al. Influence of baseline left ventricular function on the clinical outcome of surgical ventricular reconstruction in patients with ischaemic cardiomyopathy. Eur Heart J. 2013;34:39-47.

28. Meluzin J, Spinarová L, Hude P, Krejcí J, Dusek L, Vítovec J, et al. Combined right ventricular systolic and diastolic dysfunction represents a strong determinant of poor prognosis in patients with symptomatic heart failure. Int $J$ Cardiol. 2005;105:164-73.

29. Meyer P, Desai RV, Mujib M, Feller MA, Adamopoulos C, Banach M, et al. Right ventricular ejection fraction $<20 \%$ is an independent predictor of mortality but not of hospitalization in older systolic heart failure patients. Int J Cardiol. 2012; 155:120-5.
30. Giovanardi P, Tincani E, Rossi R, Agnoletto V, Bondi M, Modena MG. Righ ventricular function predicts cardiovascular events in outpatients with stable cardiovascular diseases: preliminary results. Intern Emerg Med. 2012;7:251-6.

31. Bangalore S, Yao SS, Chaudhry FA. Role of right ventricular wall motion abnormalities in risk stratification and prognosis of patients referred for stress echocardiography. J Am Coll Cardiol. 2007:50:1981-9.

32. Di Mauro M, Calafiore AM, Penco M, Romano S, Di Giammmarco G, Gallina S. Mitral valve repair for dilated cardiomyopathy: predictive role of right ventricular dysfunction. Eur Heart J. 2007;28:2510-6.

33. Itagaki S, Hosseinian L, Varghese R. Right ventricular failure after cardiac surgery: management strategies. Semin Thorac Surg. 2012;24:188-94.

34. Zornoff LA, Skali H, Pfeffer MA, St John Sutton M, Rouleau JL, Lamas GA, et al; SAVE Investigators. Right ventricular dysfunction and risk of heart failure and mortality after myocardial infarction. J Am Coll Cardiol. 2002;39:1450-5.

35. Rudski LG, Lai WW, Afilalo J, Hua L, Handschumacher MD, Chandrasekaran K, et al. Guidelines for the echocardiographic assessment of the right heart in adults: a report from the ASE endorsed by the EAE, a registered branch of the European Society of Cardiology, and the Canadian Society of Echocardiography. J Am Soc Echocardiogr. 2010;23:685-713.

Readers who found these articles interesting may also like to read the following papers found in recent and future issues of our sister publications, Seminars in Thoracic and Cardiovascular Surgery and Operative Techniques in Thoracic and Cardiovascular Surgery!

News and Views: Stephen Fremes. Outcomes of Arterial Revascularization. Semin Thorac Cardiovasc Surg. Autumn 2014;26(3): 174-175.

News and Views: Brian Buxton. Editorial on Multiple Arterial Grafting. Semin Thorac Cardiovasc Surg. Autumn 2014;26(3): 176-178.

News and Views: A. P. Kappetein. Role of PCI in the Treatment of Left Main Coronary Disease. Semin Thorac Cardiovasc Surg. Autumn 2014;26(3):187-191.

State of the Art: Victor Ferraris. Use of Anti-platelet Drugs after Cardiac Operations. Semin Thorac Cardiovasc Surg. Autumn 2014;26(3):223-230.

John Conte. Repair of Postinfarct Ventricular Septal Defect: Anterior Apical Ventricular Septal Defect. Oper Tech Thorac Cardiovasc Surg. Spring 2014;19(1):96-114.

Thomas Gleason. Repair of Postinfarction Ventricular Septal Defect: Posterior Inferior Ventricular Septal Defect. Oper Tech Thorac Cardiovasc Surg. Spring 2014;19(1):115-126. 